\title{
ANÁLISE COMPARATIVA DAS CARTEIRAS DE CRÉDITO RURAL LIBERADA COM RECURSOS DO BNDES NA COOPERATIVA SICREDI NA UNIDADE DE CAMPO NOVO DO PARECIS - MT
}

\author{
Luciano Pires dos Santos ${ }^{1}$ \\ Laércio Juarez Melz ${ }^{2}$ \\ Airton Montesuma de Carvalho Neto ${ }^{3}$ \\ Ariel Lopes Torres ${ }^{4}$
}

\section{RESUMO}

Com o crescimento da produção agrícola no país, o governo criou meios de investimento específicos para os produtores rurais, investimentos esses usados para custear a produção e comercialização do setor rural, o BNDES empresa federal é quem responsável pelos repasses aos produtores em cadeia nacional, sendo também em esfera regional, passados as cooperativas, que essas os repassam aos seus cooperados. O objetivo foi apontar as características nas concessões de créditos rurais tomados na cooperativa Sicredi em Campo Novo do Parecis-MT e comparar com operações liberadas no município de Tangará da SerraMT. O método constituiu-se de análise de documentos e relatórios oferecidos pela cooperativa Sircredi. O artigo em questão teve a finalidade de analisar a carteira de crédito rural da cooperativa de crédito Sicredi unidade de Campo Novo do Parecis no período de 2003 a 2011, identificando as linhas e suas respectivas características e evolução repassados as tipos de produtores. Concluiu-se que o maior número de tomadores concentra-se nos grandes produtores com 79,09\% dos 18 contratos liberados no período. A predominância da linha de crédito Finame Agrícola PSI, com 22,22\% do total liberado. Por fim observou-se que do total repassado, o grau de inadimplência ate a data das análise somam zero.

Palavras-chave: Cooperativismo de crédito. Investimento. Produção rural. Agronegócio.

\section{INTRODUÇÃO}

No Brasil o crescimento das cooperativas de créditos eleva a cada ano, o crédito rural tem um papel importante nesse crescimento. De acordo com a revista exame (2012), a Cooperativa de Crédito Sicredi era a terceira instituição financeira em crédito rural no país. Utilizadas também como meios de repasses de investimentos do governo federal. Caracterizase como um canal de incremento que organiza os investimentos rurais regionalizados para seus cooperados.

A expansão da agropecuária contribuiu para uma série de mudanças na história do país, tendo sido, em parte, responsável pela aceleração da mecanização das lavouras, pela modernização do sistema de transportes, pela expansão da fronteira agrícola, pela

1 Acadêmico do curso de Ciências Contábeis da UNEMAT - Campus de Tangará da Serra, email:luciano.pires.cba@gmail.com

${ }^{2}$ Mestre em Engenharia de Produção (UFSCar, 2010), Professor do curso de Ciências Contábeis da UNEMAT Campus de Tangará da Serra, e-mail: laercio@unemat.br

${ }^{3}$ Professor do curso de Ciências Contábeis da UNEMAT Campus de Tangará da Serra

${ }^{4}$ Professor do curso de Ciências Contábeis da UNEMAT Campus de Tangará da Serra 
Análise comparativa das carteiras de crédito rural liberada com recursos do BNDES na cooperativa Sicredi na unidade de Campo Novo do Parecis - MT

Luciano Pires dos Santos, Laércio Juarez Melz, Airton Montesuma de Carvalho Neto, Ariel Lopes Torres

profissionalização e incremento do comércio internacional, dentre outras contribuições (EMBRAPA, 2010).

O desenvolvimento e aplicabilidade do credito rural em Mato Grosso tem um aspecto relevante em sua economia, sendo hoje um dos estados que mais contribui no crescimento da agropecuária. O município de Campo Novo do Parecis vigora com sua economia baseada na produção de grãos. Segundo (Oliveira, 1999) as ações estimuladas pelo Estado, somadas à própria lógica de concentração do capital a partir dos grandes centros metropolitanos, fizeram surgir no campo brasileiro uma reordenação territorial, produto da combinação contraditória e desigual da expansão da agricultura. Porém, para que os cooperados possam usufruir de forma eficaz dos benefícios que o Sicredi oferece, é preciso que o beneficiário saiba das opções de crédito que ali existem, bem como a melhor forma de valer-se dele para reverter em melhoria no seu empreendimento e alcance de seus objetivos considerando, entretanto, os limites e exigências para seu acesso.

O objetivo foi apontar as características nas concessões de créditos rurais tomados na cooperativa Sicredi em Campo Novo do Parecis e comparar com operações liberadas no município de Tangará da Serra. Deste modo, este trabalho evidencia pela necessidade de maior conhecimento a respeito da destinação, objetivos atendidos, estratificação da carteira de acordo com a renda dos produtores, grau de endividamento, inadimplência da carteira, e critérios de impedimentos para associados não atendidos nos financiamentos com recursos do BNDES na agência de Campo Novo Parecis - MT, comparando com os valores em Tangará da Serra-MT.

\section{REFERENCIAL TEÓRICO}

\subsection{Sociedade Cooperativa}

Com classificação legal de constituição, as sociedades cooperativas foram criadas pela lei $n^{\circ} 5.764 / 71$, com definição especifica no (art. $6^{\circ}$ ): São as sociedades constituídas com no número mínimo de 20 pessoas físicas, sendo excepcionalmente permitida a demissão de pessoas jurídicas que tentam por objetivos as mesmas ou correlatas atividades econômicas das pessoas físicas. Podem, também, ingressar nesta sociedade outras sociedades sem fins lucrativos, atendidos, por óbvio, aos requisitos legais e estatutários.

Segundo (CRÚZIO, 2005, P.11), Cooperativas são sociedades de pessoas, com forma e natureza jurídica próprias, de natureza civil, não sujeitas à falência, constituídas para prestar 
Análise comparativa das carteiras de crédito rural liberada com recursos do BNDES na cooperativa Sicredi na unidade de Campo Novo do Parecis - MT

Luciano Pires dos Santos, Laércio Juarez Melz, Airton Montesuma de Carvalho Neto, Ariel Lopes Torres

serviços aos associados, ou seja, a unificação de trabalhos e serviços em prol do beneficio do grupo participante. Sendo sua associação por iniciativa própria e de livre ingresso para pessoas com os mesmos interesses do grupo.

Atuando tanto no setor rural quanto no urbano, as cooperativas de créditos podem se originar da associação de funcionários de uma empresa ou grupo de empresas, de profissionais de determinado segmento, de empresários ou mesmo adotar a livre admissão de associados em uma área determinada de atuação, com condições (NEWLANDS, p.28).

Sendo formadas por poupadores ou tomadores de recursos financeiros, objetivando a obtenção de crédito para seus associados a juros e prazos etc. em condições melhores do que as oferecidas pelo mercado e chegou ao Brasil, trazido da Europa pelo Padre Theodor Amstad, com o objetivo de reunir as poupanças das comunidades de imigrantes e colocá-las a serviço do seu próprio desenvolvimento. Foi em Linha Imperial, município de Nova Petrópolis, que o Padre precursor constituiu formalmente a primeira Cooperativa da espécie, em 28 de dezembro de 1902 (SCHARDONG, p.48)

O sistema de crédito cooperativo Sicredi é composto de 120 cooperativas de crédito, distribuídas em 10 estados da nossa federação: Rio Grande do Sul, Paraná, Santa Catarina, Tocantins, Rondônia, Mato Grosso, Mato Grosso do Sul, São Paulo, Pará, Goiás. Essas cooperativas reúnem, entre os seus associados, cerca de 1,8 milhões de pessoas, que atuam em diferentes atividades econômicas como produtores, empresários e promotores (SICREDI, 2012).

Desde o inicio de sua trajetória o Sistema de Crédito Cooperativo Sicredi sempre trabalhou para estar mais próximo de seus associados, buscando melhorar a qualidade de vida de cada um deles e das partes. Com o passar do tempo, foi essa relação de proximidade que acabou se tornando o principal diferencial do sistema. É por isso que se pode dizer que mais do que Sistema de Crédito Cooperativo, o Sicredi é uma organização de pessoas que preserva o relacionamento como principal ferramenta para conquistar resultados (SICREDI, 2012).

Para atender às necessidades dos associados das Cooperativas de Crédito com maior agilidade e segurança, foram criadas outras organizações que também fazem parte do sistema. São empresas corporativas que garantem produtos e serviços com especialidades, qualidades e ganhos de escala as cooperativas de crédito. Com a visão de "ser reconhecido pela sociedade como instituição financeira cooperativa, com excelência operacional e de gestão, voltada para o desenvolvimento econômico e social", as cooperativas de crédito do Sicredi atuam na captação, administração e empréstimo de recursos financeiros e prestação de serviços, agregando renda aos seus associados. (SICREDI, 2012). 
Análise comparativa das carteiras de crédito rural liberada com recursos do BNDES na cooperativa Sicredi na unidade de Campo Novo do Parecis - MT

Luciano Pires dos Santos, Laércio Juarez Melz, Airton Montesuma de Carvalho Neto, Ariel Lopes Torres

A cooperativa de Crédito de Livre admissão de associados do Sudoeste de Mato Grosso, Sicredi Sudoeste MT, foi fundada em 31 de março de 1989, na cidade de Tangará da Serra, como cooperativa de crédito rural, dando inicio a suas atividades em 21 de Setembro de 1989. No ano de 1997 passando a fazer parte do Sistema de Crédito Cooperativo, com origem no Rio Grande do Sul (ESTATUTO SOCIAL, da Cooperativa de Crédito de Livre Admissão de Associados do Sudoeste de Mato Grosso).

Percebendo uma grande evolução de mercado, com uma expectativa de crescimento e metas arrojadas, no ano de 2007 deixou de ser considerada como cooperativa de crédito rural, passando a atender como cooperativa de crédito de livre admissão, possibilitando que um maior número de pessoas pudessem se associar a cooperativa, proporcionando assim um maior crescimento e melhor atendimento de seus associados (ESTATUTO SOCIAL, da Cooperativa de Crédito de Livre Admissão de Associados do Sudoeste de Mato Grosso)

\subsubsection{BNDES}

O Banco Nacional de Desenvolvimento Econômico e Social (BNDES), empresa pública federal, é hoje o principal instrumento de financiamento de longo prazo para a realização de investimentos em todos os segmentos da economia, em uma política que inclui as dimensões social, regional e ambiental (BNDES, 2012).

Desde a sua fundação, em 1952, o BNDES se destaca no apoio à agricultura, indústria, infra-estrutura, comércio e serviços, oferecendo condições especiais para micro, pequenas e médias empresas. O Banco também vem implementando linhas de investimentos sociais, direcionados para educação e saúde, agricultura familiar, saneamento básico e transporte urbano (BNDES, 2012).O apoio do BNDES se dá por meio de financiamentos a projetos de investimentos, aquisição de equipamentos e exportação de bens e serviços. Além disso, o Banco atua no fortalecimento da estrutura de capital das empresas privadas e destina financiamentos não reembolsáveis a projetos que contribuam para o desenvolvimento social, cultural e tecnológico (BNDES, 2012).

Os financiamentos do BNDES se dão de forma direta, onde a pessoa busca recursos diretamente com a instituição do governo e de forma indireta, através da representação de instituições financeiras publicas e privadas, onde ele realiza financiamentos de longo prazo, subscrição de valores mobiliários e prestação de garantia, atuando por meio de produtos e fundos, conforme a modalidade e característica da operação. A Critério do Banco, um projeto de investimento pode se beneficiar de uma combinação de linhas de financiamento, de um 
Análise comparativa das carteiras de crédito rural liberada com recursos do BNDES na cooperativa Sicredi na unidade de Campo Novo do Parecis - MT

Luciano Pires dos Santos, Laércio Juarez Melz, Airton Montesuma de Carvalho Neto, Ariel Lopes Torres

mesmo ou de diferentes produtos, de acordo com o segmento, a finalidade do empreendimento e os itens a serem apoiados (BNDES, 2012).

As contratações de operações com recursos do BNDES, podem ser de forma automática ou não automática, onde a primeira é corresponde a financiamentos sem consulta prévia ao Banco, seguindo as condições estabelecidas para o programa/produto e a segunda para quando o financiamento é contratado a partir de uma consulta prévia ao BNDES, pois precisa de condições diferentes das estabelecidas para o programa /produto. Esse programa será encaminhado com justificativa ao BNDES e, se aprovado, será expedido a autorização com prazo de validade, critérios e condições de financiamento (SICREDI, 2012).

\subsubsection{Linhas do BNDES no Sicredi}

Para oferecer os financiamentos oferecidos pelo BNDES, o Sicredi acessa algumas linhas de crédito disponíveis pelo Banco, sendo elas: BNDES PSI Agropecuário; Procaminhoneiro; Moderagro; Moderfrota; Moderinfra; Propflora; Produsa e PSI BKAquisição. (SICREDI, 2012).

Esta linha de crédito disponibilizada pelo Sicredi tem como objetivo financiar a produção e a aquisição isolada de máquinas e equipamentos novos, inclusive agrícolas, ônibus, caminhões, chassis, caminhões-tratores, carretas, cavalos-mecânicos, reboques, semireboques, aí incluídos os tipo tanques e afins, novos; fabricados no país, credenciados no BNDES; a aquisição de máquinas e equipamentos novos, fabricados no país, credenciados no BNDES no âmbito de projeto de investimento; a aquisição daqueles bens destinados a operações de arrendamento mercantil; e o capital de giro associado à aquisição isolada de máquinas e equipamentos. (BNDES, 20012c)

A linha BNDES PSI oferece taxas de juros que variam de 4,5\% a 7,0\% ao ano, sendo que dependendo do item financiado e de acordo com o porte da empresa, o limite de financiamento pode variar de $80 \%$ a até $100 \%$ do valor total do bem adquirido. (BNDES, 2002c).

Tem por objetivo o atendimento aos associados que desejam adquirir caminhões, chassis, caminhões-tratores, carretas, cavalos-mecânicos, reboques, semi-reboques e carrocerias para caminhões novos e usados de fabricação nacional. (BNDES, 2012a)

Poderão ser beneficiários deste programa pessoas físicas residentes e domiciliadas no pais, empresários individuais ou microempresas do segmento de transporte rodoviário de 
Análise comparativa das carteiras de crédito rural liberada com recursos do BNDES na cooperativa Sicredi na unidade de Campo Novo do Parecis - MT

Luciano Pires dos Santos, Laércio Juarez Melz, Airton Montesuma de Carvalho Neto, Ariel Lopes Torres

carga, com renda anual igual ou inferior a $\mathrm{R} \$ 2.400 .000,00$ (dois milhões e quatrocentos mil reais). (BNDES, 2012a)

A taxa de juros correspondente ao Procaminhoneiro pode ser fixa ou variável, onde para a primeira será de 4,5\% ao ano e a variável corresponderá ao somatório de custo financeiro, remuneração básica do BNDES e Remuneração da instituição financeira credenciada. (BNDES, 2012a).

A linha Moderagro que significa Programa de Modernização da Agricultura e Conservação de Recursos Naturais é o programa que disponibiliza recursos para o financiamento de projetos destinados aos diversos setores da pecuária, floricultura, fruticultura e horticultura. Possui como objetivo principal o apoio ao desenvolvimento da produção de espécies de frutas com potencial mercadológico interno e externo e fomentar os setores da apicultura, aqüicultura, pesca, avicultura, floricultura etc. (BNDES, 2012b)

A taxa de juros adequada a esta modalidade é fixa em $6,75 \%$ ao ano, sendo que a operação pode ter um prazo de 120 meses quando se tratar de operação relativas as atividades de suinocultura ou avicultura e até 96 meses nos demais casos. (BNDES, 2012b)

A linha Moderfrota é o programa que disponibiliza recursos para o financiamento de tratores, colheitadeiras e implementos novos ou usados e equipamentos para o preparo, secagem e beneficiamento do café. (BNDES, 2012c)

Como principal característica atrativa, a linha Moderfrota apresenta as formas de pagamentos, que podem ser Semestrais ou Anuais. Possui valor mínimo de financiamento de $\mathrm{R} \$ 1.000,00$ (Hum mil reais) e o valor máximo de $\mathrm{R} \$ 200.000,00$ (Duzentos mil reais) para aquisição que pode variar de acordo com o tipo de associado, bem a ser adquirido, tempo da operação e etc. O limite de financiamento se dá em $90 \%$ do valor total do bem. (BNDES, 2010c)

Moderinfra é o programa de incentivo a irrigação, armazenagem e à proteção da fruticultura contra a incidência de granizo. Disponibiliza recursos para o desenvolvimento da agricultura irrigada, sustentável tanto economicamente quanto ambientalmente, para a ampliação da capacidade de armazenamento de propriedade rural e para apoiar a fruticultura em regiões de clima temperado contra a incidência de granizo. (BNDES, 2012d)

Com o Moderinfra, busca-se minimizar os riscos de produção, possibilitar o aumento da oferta de alimento para os mercados internos e externos, ampliar a capacidade de armazenamento nas propriedades rurais e apoiar a fruticultura em regiões de clima temperado contra incidência de granizo. (BNDES, 2012d) 
Análise comparativa das carteiras de crédito rural liberada com recursos do BNDES na cooperativa Sicredi na unidade de Campo Novo do Parecis - MT

Luciano Pires dos Santos, Laércio Juarez Melz, Airton Montesuma de Carvalho Neto, Ariel Lopes Torres

Beneficia produtores rurais pessoa física, jurídica ou cooperativa de produtores rurais com investimentos fixos e semi-fixos relacionados com todos os itens inerentes aos sistemas de irrigação, armazenamento e proteção da fruticultura contra a incidência de granizo, inclusive as cercas de sustentação dessas estruturas, contemplando implantação, ampliação, reforma ou recuperação, adequação ou modernização desses itens de forma coletiva ou individual. (BNDES, 2012d)

Esta linha apresenta limite mínimo de financiamento de $\mathrm{R} \$ 1.000,00$ (Um mil reais) e máximo de $\mathrm{R} \$ 1.000 .000,00$ (Um milhão de reais), sendo que podem ser beneficiados até $100 \%$ dos itens financiados. Dependendo ainda da extensão do projeto, a operação poderá ter uma duração de até 144 meses, com uma carência de até 36 meses. (BNDES, 2010d)

Propflora é um programa de plantio comercial e recuperação de florestas. É um programa do BNDES para disponibilização de recursos ao financiamento de projetos de plantio e recuperação de florestas.

Ele possui como objetivos principais a implantação e manutenção de florestas destinadas ao uso industrial (siderúrgica, serrarias, papel e celulose); recomposição e manutenção de áreas de preservação e reserva florestal legal; implantação e manutenção de espécies florestais para a produção de madeira destinada a produção de carvão vegetal; implantação de projetos agroflorestais (agricultura, consorciada com florestas) e implantação e manutenção de florestas de dendezeiro.

Os beneficiários desta linha podem ser Produtores rurais, pessoas físicas ou jurídicas, cooperativas de produtores rurais e associações de produtores rurais que desejam fazer investimentos fixos ou semi-fixos, inclusive os relacionados ao sistema de exploração denominado manejo florestal, implantação de viveiros de mudas florestais e custeio de projetos de investimentos, limitado a $35 \%$ do valor do investimento, relacionado com gastos de manutenção no segundo, terceiro e quarto anos.

Este programa possui um limite mínimo de atendimento por associado de $\mathrm{R} \$ 1.000,00$ (Hum mil reais) e máximo de $\mathrm{R} \$ 300.000,00$ (Trezentos mil reais), onde é admitida a concessão de mais de um financiamento para o mesmo associado,em cada ano safra, desde que a atividade assistida exija e que o somatório não ultrapasse o limite máximo exposto acima. (BNDES, 2012e)

O Pronaf é um programa de apoio ao desenvolvimento rural, a partir do fortalecimento da agricultura familiar como segmento gerador de postos de trabalho e renda. É um programa do BNDES que visa a disponibilização de recursos aos financiamentos dos 
Análise comparativa das carteiras de crédito rural liberada com recursos do BNDES na cooperativa Sicredi na unidade de Campo Novo do Parecis - MT

Luciano Pires dos Santos, Laércio Juarez Melz, Airton Montesuma de Carvalho Neto, Ariel Lopes Torres

produtores familiares em suas diversas atividades agropecuárias e não agropecuárias desenvolvida na área rural ou fora dela.

Esta é uma linha de crédito especifica para produtores familiares, que se divide em três subgrupos, sendo elas:

- $\quad$ Pronaf Mais alimentos que é destinada ao financiamento de projetos para produção armazenagem e transportes de açafrão, arroz, café, cana-de-açúcar, centeio, erva mate, feijão, mandioca, milho, soja, sorgo, trigo, fruticultura, palmeiras para produção de pamito, olericultura, apicultura, aqüicultura, avicultura, bovinocultura de corte, bovinocultura de leite, caprinocultura, ovinocultura, pesca e suinocultura.

- Pronaf Mulher que é destinado ao atendimento de propostas de crédito de mulher agricultora, conforme projeto técnico ou proposta simplificada.

- Pronaf convencional que é destinado aos investimentos de implantação, ampliação ou modernização da infraestrutura de produção e serviços agropecuários no estabelecimento comercial ou em áreas comunitárias rurais próximas.

Por ser uma linha de financiamento de incentivo a agricultura familiar, esta linha de crédito não permite o financiamento da mão de obra do própria, seja, do proponente ou do seu núcleo familiar, seja de funcionários do proponente. São passiveis de financiamento através do Pronaf os seguintes itens: Construção e reforma ou ampliação de benfeitorias e instalações permanentes; Obras de irrigação, açudagem, drenagem, proteção e recuperação do solo; Desmatamento e destoca, florestamento, reflorestamento; formação ou recuperação de pastagens; Veículos de carga, automotores, elétricos ou de tração animal, adequados as condições rurais, e etc.

O programa Pronaf Mais alimentos disponibiliza financiamentos com limite mínimo de $\mathrm{R} \$ 1.000,00$ (Hum mil reais) até $\mathrm{R} \$$ 130.000,00 (Cento e trinta mil reais) com encargos de 2\% ao ano. Já o programa Pronaf Convencional e Pronaf Mulher, o valor do financiamento oscila de $\mathrm{R} \$$ 10.000,00 (Dez mil reais) até $\mathrm{R} \$$ 50.000,00 (Cinquenta mil reais) onde os encargos do financiamento também oscilam de $1 \%$ a até $4 \%$ ao ano de acordo com o valor tomado. (BNDES, 2012a)

Produsa é um programa do BNDES que significa Programa de Estimulo a Produção Agropecuária Sustentável. Com enfoque ambiental, o Produsa assume um papel relevante à necessidade de expansão da produção com controle de avanço sobre biomas naturais por lavouras ou pecuárias, dadas as limitações da legislação ambiental e a necessidade de evitar o aumento da emissão de gases de efeito estufa. 
Análise comparativa das carteiras de crédito rural liberada com recursos do BNDES na cooperativa Sicredi na unidade de Campo Novo do Parecis - MT

Luciano Pires dos Santos, Laércio Juarez Melz, Airton Montesuma de Carvalho Neto, Ariel Lopes Torres

O Produsa é sustentado por dois objetivos principais, sendo o primeiro, estimular a recuperação de áreas degradadas, inclusive pastagens, reinserindo-as no processo produtivo, fomentando a adoção de sistemas sustentáveis, conforme a legislação ambiental e por segundo, expandir a produção da pecuária e agrícola sem necessidade de aumentar a área de pastagens e evitar desmatamentos e avanços sobre o bioma amazônico.

Para ser atendido pela linha Produsa, o associado precisa estar enquadrado como produtor rural, pessoa física ou jurídica ou como cooperativa de produtores rurais. Tem como limite de financiamento, até $\mathrm{R} \$ 400.000,00$ (Quatrocentos mil reais) por beneficiário para projetos produtivos destinados a recuperação de áreas degradadas e de até $R \$ 300.000,00$ (Trezentos mil reais) por beneficiário para os demais casos de financiamento. É uma linha que oferece como prazo máximo para a operação de 60 a até 144 meses, dependendo da destinação do crédito, podendo ter até 36 meses de carência. (BNDES, 2012)

A linda de crédito PSI BK Aquisição Financia a aquisição de máquinas e equipamentos novos, fabricados no país, credenciados no BNDES no âmbito de projeto de investimento, tendo como beneficiários Pessoas jurídicas, sociedades nacionais e estrangeiras, com sede e administração no Brasil, cooperativas, associações e fundações, condomínios e assemelhados, e clubes acordo com os normativos do BNDES. Itens financiáveis, máquinas e equipamentos novos, inclusive agrícolas, aí incluídos conjuntos e sistemas industriais, máquinas-ferramenta, aeronaves, vagões e locomotivas ferroviários e metroviários, tratores, colheitadeiras, implementos agrícolas e máquinas rodoviárias e equipamentos para pavimentação, de acordo com os normativos do BNDES, com o limite de no máximo 10 (milhões de reais) com carência de 24 meses e prazo de amortização de 120 meses, com taxa de juros de $6,5 \%$ a $8,7 \%$, de acordo com a receita operacional do grupo econômico.(BNDES, 2012f)

\section{METODOLOGIA}

Esta pesquisa se caracteriza como bibliográfica, descritiva e documental. Segundo Vergara (2011), pesquisa bibliográfica é o estudo sistematizado desenvolvido com base em material, podendo ser classificada quanto aos seus objetivos como pesquisa quantitativa e descritiva, que conforme Gil (2008), as pesquisas descritivas têm como objetivo primordial à descrição das características de determinados fenômeno ou o estabelecimento de relações entre as variáveis. Através da análise de documentos fornecidos pela Cooperativa Sicredi, em 
Análise comparativa das carteiras de crédito rural liberada com recursos do BNDES na cooperativa Sicredi na unidade de Campo Novo do Parecis - MT

Luciano Pires dos Santos, Laércio Juarez Melz, Airton Montesuma de Carvalho Neto, Ariel Lopes Torres

que ao aplicar fórmulas e efetuar relações entre os dados, consegue-se descrever as características das linhas de crédito e dos tomadores de crédito na Cooperativa Sicredi com recursos do BNDES na agência de Campo Novo do Parecis - MT.

Foram realizadas análises de documentos referentes à concessão de crédito da Cooperativa Sicredi entre os anos de 2003 a 2011, em 18 contratos liberados neste período. Através de relações e aplicações estatísticas podem-se demonstrar alguns índices importantes para a análise de resultados e evolução do crédito rural investido com recursos repassados. Alguns resultados foram comparado com pesquisa realizada na agência de Tangará da Serra, em estudo realizado por Leite et al (2012).

Com esta análise ficou evidenciado quais as características das linhas de crédito praticadas em Campo Novo do Parecis - MT, em consequência, apontando as características dos associados mais atendidos. Foram também demonstradas suas principais características e relacionando os créditos mais concedidos com o perfil dos associados mais atendidos. Levantando ainda os valores anualmente aplicados por linha de crédito, demonstrando a evolução de volume de créditos concedidos conforme os anos de atuação da cooperativa. Foram realizadas entrevistas com agentes da instituição financeira encarregados das modalidades de financiamento analisadas.

\section{RESULTADOS}

A pesquisa foi aplicada em documentos internos cedidos pela unidade de atendimento da cooperativa de crédito Sicredi de Campo Novo do Parecis, que teve sua abertura aos cooperados no ano de 2002. Nessa região vigora tem como principal atividade a produção de grãos em larga escala. Existe maior predominância de médio e grande produtores rurais comparados a outras regiões circunvizinhas.

Para melhor visualização dos resultados obtidos foram apresentados em tabelas, evidenciando em números o problema citado. Tendo como objetivos apontar as características nas concessões de créditos rurais tomados na cooperativa Sicredi em Campo Novo do Parecis e comparação com operações liberadas no município de Tangará da Serra.

Apresentado a tabela 1, demostra quantidade de contratos de créditos por tipo de produtor, a participação em percentual, valores tomados em reais e percentuais. Conforme explicado, ocorre a divisão dos produtores conforme sua renda média anual. Considera-se que o mini produtor aquele com renda até $\mathrm{R} \$ 150$ mil anuais; pequeno produtor com renda entre 
Análise comparativa das carteiras de crédito rural liberada com recursos do BNDES na cooperativa Sicredi na unidade de Campo Novo do Parecis - MT

Luciano Pires dos Santos, Laércio Juarez Melz, Airton Montesuma de Carvalho Neto, Ariel Lopes Torres

$\mathrm{R} \$ 150$ mil a $\mathrm{R} \$ 300$ mil anuais; médio produtor, com renda entre $\mathrm{R} \$ 300$ mil a $\mathrm{R} \$ 1,9$ milhão anuais; Grande produtor, com renda acima de R\$1,9 milhão anuais.

Tabela 1- Participação quantitativa do tipo de produtores nos contratos liberados de 2003 a 2011

\begin{tabular}{ccccc}
\hline $\begin{array}{c}\text { Tipo de } \\
\text { Produtor }\end{array}$ & $\begin{array}{c}\text { Quantidade de } \\
\text { Contratos } \\
\text { Liberados }\end{array}$ & $\begin{array}{c}\text { Part. No total de } \\
\text { Contratos }\end{array}$ & Soma de Valor Titulo & $\begin{array}{c}\text { Participação no total do } \\
\text { valor financiado }\end{array}$ \\
\hline Grande Produtor & 11 & $61,11 \%$ & $2.941 .840,00$ & $79,09 \%$ \\
Médio Produtor & 5 & $27,78 \%$ & $727.750,00$ & $19,57 \%$ \\
Mini Produtor & 2 & $11,11 \%$ & $50.000,00$ & $1,34 \%$ \\
Total Geral & $\mathbf{1 8}$ & $100,00 \%$ & $\mathbf{3 . 7 1 9 . 5 9 0 , 0 0}$ & $100,00 \%$ \\
\hline
\end{tabular}

A partir dos 18 contratos liberados no, entre 2003 e 2010, observou-se o total de R\$ 3.719.591,00. A maior soma de valores financiados foi liberada para grandes produtores. Foram concedidos R 2.941 .840 participação de 79,09\% do total liberado. A participação dos mini produtores foi de $1,34 \%$ do total liberado. A tabela 2 demostra a classificação das áreas destes produtores. O valor médio dos contratos para cada categoria foi $\mathrm{R} \$ 267.440,00$ para os grandes produtores, $\mathrm{R} \$ 145.550,00$ para os médios e $\mathrm{R} \$ 25.000,00$ para os pequenos. O maior contrato liberado para grandes produtores teve valor de $\mathrm{R} \$ 1.000 .000,00$ e o menor $\mathrm{R} \$$ 20.000,00. Para médios produtores, o maior contrato foi de $\mathrm{R} \$ 324.000,00$. Os dois contratos de mini produtores tinham o maior $\mathrm{R} \$ 30.000,00$ e o menor $\mathrm{R} \$ 20.000,00$.

Conforme Leite et al (2012), em Tangará da Serra no período de 2005 a 2011, dos 92 contratos de créditos liberados com recurso do BNDES, $41 \%$ foram liberados aos mini produtores. Caracterizando diferença da pesquisa realizada em Campo Novo do Parecis. Outro aspecto relevante na comparação das pesquisas são os valores médios em reais por número de contratos. Campo Novo do Parecis apresentou média R\$206.646,00, contra 106.798,70 de Tangará da Serra por contrato.

A tabela 2 mostra as áreas, em hectares, utilizadas pelos tipos de produtores. Concentrando 61,11\% nas áreas acima de 2000 hectares. Os contratos cuja área beneficiada foi de, 1 a 500 hectares representaram 16,67\%. A de 501 a 1000 e 1001 a 2000 hectares, discriminadas no contrato representaram, ambas, 11,11\%. A predominância ocorre novamente com os grandes produtores com participação de $61,11 \%$ nas quatro classificações de áreas rurais. $50 \%$ do total de contratos foram celebrados com Grandes produtores com áreas maiores que 2000 hectares. Pode-se perceber que há 11,11\% de médios produtores com áreas acima de 2000 hectares. Isso acontece porque a classificação de grande, médio e mini foi feita com base nos valores de renda e não pela área da propriedade. 
Análise comparativa das carteiras de crédito rural liberada com recursos do BNDES na cooperativa

Sicredi na unidade de Campo Novo do Parecis - MT

Luciano Pires dos Santos, Laércio Juarez Melz, Airton Montesuma de Carvalho Neto, Ariel Lopes Torres

\begin{tabular}{cccccc}
\hline \multicolumn{7}{c}{ Tabela 2 - Classificação da amostra de acordo com a área do produtor } \\
\hline Tipo de Produtores & $\begin{array}{c}\text { Acima de 2000 } \\
\text { Hectares }\end{array}$ & $\begin{array}{c}\text { De 1 a 500 } \\
\text { Hectares }\end{array}$ & $\begin{array}{c}\text { De 1001 a } \\
\mathbf{2 0 0 0} \\
\text { Hectares }\end{array}$ & $\begin{array}{c}\text { De 501 a 1000 } \\
\text { Hectares }\end{array}$ & Total geral \\
\hline Grande Produtor & $50,00 \%$ & $5,56 \%$ & $5,56 \%$ & $0,00 \%$ & $61,11 \%$ \\
Médio Produtor & $11,11 \%$ & $5,56 \%$ & $5,56 \%$ & $5,56 \%$ & $27,78 \%$ \\
Mini Produtor & $0,00 \%$ & $5,56 \%$ & $0,00 \%$ & $5,56 \%$ & $11,11 \%$ \\
Total geral & $\mathbf{6 1 , 1 1 \%}$ & $\mathbf{1 6 , 6 7 \%}$ & $\mathbf{1 1 , 1 1 \%}$ & $\mathbf{1 1 , 1 1 \%}$ & $\mathbf{1 0 0 , 0 0 \%}$ \\
\hline
\end{tabular}

Considerando tipo de produtores e linhas de créditos, na tabela 3, observa-se que dos 18 contratos liberados nos períodos analisados e classificados dentro das 6 modalidades de linhas de crédito, a modalidade de FINAME Agrícola concentra 22,22\% e todos estes são classificados como grandes produtores. Os produtores de médio porte somaram mais empréstimos na linha MODERAGRO, 16,67\%. Os dois mini produtores utilizaram as linhas MODERAGRO e PROSOLO. A linha de crédito mais utilizada por todos foi MODERAGRO, representando 33,33\% do total de empréstimos concedidos.

Segundo Leite et al (2012), em Tangará da Serra do 32,68 \% dos contratos foram liberados na linha de crédito FINAME Agrícola.

Tabela 3 -Classificação dos produtores nas modalidades de créditos liberados

\begin{tabular}{|c|c|c|c|c|c|c|c|}
\hline $\begin{array}{c}\text { TIPO DE } \\
\text { PRODUTOR }\end{array}$ & $\begin{array}{c}\text { FINAME } \\
\text { AGRICOLA PSI } \\
\end{array}$ & $\begin{array}{c}\text { MODER } \\
\text { AGRO }\end{array}$ & $\begin{array}{l}\text { MODER } \\
\text { FROTA } \\
\end{array}$ & PRODUSA & PROSOLO & $\begin{array}{c}\text { PSI BK - } \\
\text { AQUISIÇÃO }\end{array}$ & $\begin{array}{l}\text { Total } \\
\text { geral }\end{array}$ \\
\hline Grande Produtor & $22,22 \%$ & $16,67 \%$ & $5,56 \%$ & & $11,11 \%$ & $5,56 \%$ & $61,11 \%$ \\
\hline Médio Produtor & & $11,11 \%$ & $5,56 \%$ & $5,56 \%$ & $5,56 \%$ & & $27,78 \%$ \\
\hline Mini Produtor & & $5,56 \%$ & & & $5,56 \%$ & & $11,11 \%$ \\
\hline Total geral & $22,22 \%$ & $33,33 \%$ & $11,11 \%$ & $5,56 \%$ & $22,22 \%$ & $5,56 \%$ & $100,00 \%$ \\
\hline
\end{tabular}

As garantias tem papel importante nos contratos de créditos. Elas podem ser, pessoal ou real, ou mesmo somadas. A tabela 4 mostra garantias pactuadas nos contratos de créditos. Percebeu-se que dos 18 contratos liberados distribuídos nas linhas de créditos, a modalidade de Moderagro, teve 6 contratos liberados com garantia real aval, com participação de 33,33\% no total. A modalidades Finame e Prosolo, ambas tiveram 4 contratos correspondendo a 22,22\% cada, do total de contratos. A linha Moderfrota, com 2 contratos liberados sendo um com garantia de aval e outro com aval juntamente com Penhor Mercantil, somando 11,11\% do total. 
Análise comparativa das carteiras de crédito rural liberada com recursos do BNDES na cooperativa Sicredi na unidade de Campo Novo do Parecis - MT

Luciano Pires dos Santos, Laércio Juarez Melz, Airton Montesuma de Carvalho Neto, Ariel Lopes Torres

\begin{tabular}{cccccccc}
\hline \multicolumn{6}{c}{ Tabela 4 - Classificação das garantias nos contratos liberados com relação às modalidades } \\
\hline Lindas de Créditos & $\begin{array}{c}\text { Alienação } \\
\text { fiduciária }\end{array}$ & $\begin{array}{c}\text { Alienação } \\
\text { fiduciária } \\
\text { e Aval }\end{array}$ & $\begin{array}{c}\text { Alienação } \\
\text { fiduciária } \\
\text { e Hipoteca }\end{array}$ & Aval & $\begin{array}{c}\text { Aval e } \\
\text { Penhor } \\
\text { Mercantil }\end{array}$ & $\begin{array}{c}\text { Hipoteca e } \\
\text { Alienação } \\
\text { fiduciária }\end{array}$ & $\begin{array}{c}\text { Total } \\
\text { geral }\end{array}$ \\
\hline FINAME AGRICOLA PSI & $5,56 \%$ & $5,56 \%$ & $5,56 \%$ & & & $5,56 \%$ & $22,22 \%$ \\
MODERAGRO & & & $5,56 \%$ & $33,33 \%$ & & $5,56 \%$ & $3,33 \%$ \\
MODERFROTA & & & & $5,56 \%$ & & $5,11 \%$ \\
PRODUSA & & $5,56 \%$ & & $22,22 \%$ & & $5,56 \%$ \\
PROSOLO & & & & & & $5,22 \%$ \\
PSI BK - AQUISIÇÃO & $\mathbf{5 , 5 6 \%}$ & $\mathbf{1 1 , 1 1 \%}$ & $\mathbf{1 1 , 1 1 \%}$ & $\mathbf{6 1 , 1 1 \%}$ & $\mathbf{5 , 5 6 \%}$ & $\mathbf{5 , 5 6 \%}$ & $\mathbf{1 0 0 , 0 0 \%}$ \\
Total geral & & & & & & &
\end{tabular}

De acordo com a tabela 5, a linha de credito mais operada é a Finame Agrícola PSI, com um volume de R $\$ 1.532 .240,00$ correspondendo 41,19\% do total, seguido pelo PSI BKAquisição com 1.000.000,00 as outras linhas não atingiram a faixa de 1milhão dos valores liberados.

Destaca-se também na tabela a variação dos valores liberado nos anos analisados, concentrando uma grande evolução no ano de 2010 com mais de 1 milhão liberados, tendo uma leve baixa no ano de 2011.

Segundo Leite et al (2012), em Tangará da Serra 32,68 \% dos contratos foram liberados na linha de crédito FINAME Agrícola, somando valor de R\$3.180.925,85.

Tabela 5 -Distribuição do valor financiado por modalidade e por ano contratado ( Valores em R\$)

\begin{tabular}{cccccccc}
\hline Linha de Crédito & $\mathbf{2 0 0 3}$ & $\mathbf{2 0 0 7}$ & $\mathbf{2 0 0 8}$ & $\mathbf{2 0 0 9}$ & $\mathbf{2 0 1 0}$ & $\mathbf{2 0 1 1}$ & Total geral \\
\hline FINAME AGRICOLA PSI & & & & & $893.240,00$ & $639.000,00$ & $1.532 .240,00$ \\
MODERAGRO & & $280.000,00$ & $200.000,00$ & & & & $480.000,00$ \\
MODERFROTA & $49.600,00$ & & & $324.000,00$ & & & $373.600,00$ \\
PRODUSA & & & & & & $213.750,00$ & $213.750,00$ \\
PROSOLO & $120.000,00$ & & & & $1.000 .000,00$ & $120.000,00$ \\
PSI BK - AQUISIÇÃO & & & & & $\mathbf{8 5 0 0 0 0 0 0}$ \\
Total geral & $\mathbf{1 6 9 . 6 0 0 , 0 0}$ & $\mathbf{2 8 0 . 0 0 0 , 0 0}$ & $\mathbf{2 0 0 . 0 0 0 , 0 0}$ & $\mathbf{3 2 4 . 0 0 0 , 0 0}$ & $\mathbf{1 . 8 9 3 . 2 4 0 , 0 0}$ & $\mathbf{8 5 2 . 7 5 0 , 0 0}$ & $\mathbf{3 . 7 1 9 . 5 9 0 , 0 0}$ \\
\hline
\end{tabular}

Na sequencia a tabela 6 demostra os números de contratos por cada modalidade nas linhas de créditos, identificando a real situação dos contratos, se já foram liquidados, ou vigente e se inadimplente.

Tabela 6 - Análise quantitativa da situação dos contratos liberados em relação as modalidades

\begin{tabular}{cccccc}
\hline Linhas de Crédito & Total geral & Liquidado & Normal & Inadimplente & Part. Geral \\
\hline FINAME AGRICOLA PSI & 4 & & 4 & 0 & $22,22 \%$ \\
MODERAGRO & 6 & 3 & 3 & 0 & $33,33 \%$ \\
MODERFROTA & 2 & 1 & 1 & 0 & $11,11 \%$ \\
PRODUSA & 1 & & 1 & 0 & $5,56 \%$ \\
PROSOLO & 4 & 4 & & 0 & $22,22 \%$ \\
PSI BK - AQUISIÇÃO & 1 & & 1 & 0 & $5,56 \%$ \\
Total geral & $\mathbf{1 8}$ & $\mathbf{8}$ & $\mathbf{1 0}$ & $\mathbf{0}$ & $\mathbf{1 0 0 , 0 0 \%}$ \\
\hline
\end{tabular}


Análise comparativa das carteiras de crédito rural liberada com recursos do BNDES na cooperativa Sicredi na unidade de Campo Novo do Parecis - MT

Luciano Pires dos Santos, Laércio Juarez Melz, Airton Montesuma de Carvalho Neto, Ariel Lopes Torres

Deste modo, do volume de crédito liberado com repasse do BNDES, no período de 2003 a 2011, pela Cooperativa de Crédito Sicredi Sudoeste na unidade de atendimento do município de Campo Novo do Parecis, não existiu inadimplência, ate a data da coleta dos dados. Ocorre que do total dos contratos liberados 44,44\% já foram liquidados, restando somente 55,56\% em situação vigente. A análise nos contratos liberados permitiu a evidenciação de características financeira, apresentados em médias na tabela 07.

Tabela 07 - Demonstração de taxa, carência e prazo dos contratos liberados

\begin{tabular}{ccccc}
\hline Linhas de Créditos & $\begin{array}{c}\text { Números de } \\
\text { Contratos }\end{array}$ & $\begin{array}{c}\text { Taxa média } \\
\text { (ano) }\end{array}$ & $\begin{array}{c}\text { Carência } \\
\text { média (ano) }\end{array}$ & Prazo médio (ano) \\
\hline FINAME AGRICOLA PSI & 4 & $5,50 \%$ & 5 & 6 \\
MODERAGRO & 6 & $6,75 \%$ & 0 & 5 \\
MODERFROTA & 2 & $11,12 \%$ & 0 & 10 \\
PRODUSA & 1 & $6,75 \%$ & 12 & 4 \\
PROSOLO & 4 & $8,75 \%$ & 0 & 5 \\
PSI BK - AQUISIÇÃO & 1 & $5,50 \%$ & 11 & 4 \\
Média do total & $\mathbf{3}$ & $\mathbf{7 , 4 0 \%}$ & $\mathbf{4 , 6 7}$ & $\mathbf{5}$ \\
\hline
\end{tabular}

Por fim, dentre os 18 contratos de crédito liberados, obtiveram como média de juros de 7,40\% ao ano, apresentando ainda carência média de 4,67 (ano) em seguida os contratos tiveram 5,74 de prazo médio para sua quitação. Ressaltando que todas as linhas são de longo prazo dando assim ao produtor maior tempo pra pagar, tendo o prazo de carência como base para produzir e em seguida começar a amortizar as parcelas do contrato.

\section{CONCLUSÃO}

De acordo com analise, pode-se concluir que no período de 2003 a 2011, os contratos de créditos liberados com recurso do BNDES repassados pela cooperativa de créditos Sicredi de Campo Novo do Parecis - MT, teve evolução significativas.

O grande produtor, ficou com 79,09\% do total do volume liberados, levando em consideração que Campo Novo do Parecis. Em 2012 se encontrava como um dos maiores produtores de grão do estado. Assim eleva a quantidade de grande produtores rurais, dando este reflexo no total de liberações no Sicredi, os minis produtores por terem áreas menores para plantar, ficaram com $1,34 \%$ do volume liberados no período.

Dando evidenciação ao objetivo do trabalho, percebeu-se que de todas as linhas de créditos utilizadas pelo Sicredi para repasses, a que predominou em volume foi a FINAME Agrícola com 22,22\% do total liberado. Se constitui como operação de longo prazo com taxa de juro de 5,5 ao ano carência para começar a pagar de 5 anos e prazo de 8 anos. Percebeu-se que para a liberação de créditos existem políticas e fatores exigidos pelo agente financeiro, no 
Análise comparativa das carteiras de crédito rural liberada com recursos do BNDES na cooperativa Sicredi na unidade de Campo Novo do Parecis - MT

Luciano Pires dos Santos, Laércio Juarez Melz, Airton Montesuma de Carvalho Neto, Ariel Lopes Torres

caso a cooperativa de crédito. Quanto às garantias exigidas nos contratos liberados, dos 18 contratos de créditos liberados a garantia real, pessoal, do aval participou com $61,11 \%$ nas distribuídos nas linhas de crédito. Dos contratos liberados no período analisado, por se tratarem de contratos rurais e de longo prazo, dos 18 contratos liberados, 10 ainda continuam dentro do prazo e 8 foram liquidados. Nenhum contrato em situação de inadimplência no período analisado.

\section{REFERÊNCIAS}

BNDES.Histórico. Disponível em <http://www.bndes.gov.br/SiteBNDES/bndes/bndes _pt/institucional/O_BNDES/A_Empresa/>. Acesso em 17.03.2012.

, Banco Nacional de Desenvolvimento Econômico e Social. 2006a.Circular n $\mathbf{n}^{\mathbf{0}} 198$ de 18 de Agosto de 2006 do BNDES: dispõe sobre as normas reguladoras do produto Pronaf. Mimeo.

Banco Nacional de Desenvolvimento Econômico e Social. 2006c. Carta Circular $\mathbf{n}^{\mathbf{0}}$ 197 de 18 de Agosto de 2006 do BNDES.dispõe sobre as normas reguladoras do produto Sustentação do Investimento (BNDES PSI). Mimeo.

Banco Nacional de Desenvolvimento Econômico e Social. 2010a. Circular n⿳ 54 de 04 de Novembro de 2010 do BNDES.dispõe sobre as normas reguladoras do produto BNDES Procaminhoneiro. Mimeo.

Banco Nacional de Desenvolvimento Econômico e Social. 2010b. Circular $\mathbf{n}^{\mathbf{0}} 16$ de 16 de Julho de 2010 do BNDES.dispõe sobre as normas reguladoras do produto Moderagro. Mimeo.

, Banco Nacional de Desenvolvimento Econômico e Social. 2010c. Carta Circular $\mathbf{n}^{\mathbf{o}}$ 17 de 16 de Julho de 2010 do BNDES.dispõe sobre as normas reguladoras do produto Moderfrota. Mimeo.

Banco Nacional de Desenvolvimento Econômico e Social. 2010d. Circular $\mathbf{n}^{\mathbf{0}} 18$ de 16 de Julho de 2010 do BNDES.dispõe sobre as normas reguladoras do produto Moderinfra. Mimeo.

, Banco Nacional de Desenvolvimento Econômico e Social. 2010e. Circular $\mathbf{n}^{\mathbf{0}} 19$ de 16 de Julho de 2010 do BNDES.dispõe sobre as normas reguladoras do produto Propflora. Mimeo.

Banco Nacional de Desenvolvimento Econômico e Social. 2010f. Circular $\mathbf{n}^{\mathbf{0}} 20$ de 16 de Julho de 2010 do BNDES.dispõe sobre as normas reguladoras do produto Produsa. Mimeo.

, Banco Nacional de Desenvolvimento Econômico e Social. 2012e. Circular no 21 de 16 de Julho de 2010 do BNDES.dispõe sobre as normas reguladoras do produto PSI BK Aquisição. Mimeo. 
Análise comparativa das carteiras de crédito rural liberada com recursos do BNDES na cooperativa Sicredi na unidade de Campo Novo do Parecis - MT

Luciano Pires dos Santos, Laércio Juarez Melz, Airton Montesuma de Carvalho Neto, Ariel Lopes Torres CRÚZIO, Helnon de Oliveira. Como Organizar Uma Cooperativa. 4.ed. Rio de Janeiro: FGV, 2005.

GIL, Antonio Carlos. Métodos e Técnicas de Pesquisa Social. 6. ed. São Paulo: Atlas, 2008.

LEITE, Flavio Henrique Colla; et al. Análise da carteira de crédito rural liberada com recursos do BNDES na cooperativa SICREDI na unidade de Tangará da Serra - MT. In: 50. Congresso da Sober, 2012. Disponível em:

<http://icongresso.itarget.com.br/useradm/anais/?clt=ser.2〉. Acesso em: 17 out. 2012.

NEWLANDS, Junior, Carlos Arthur; Sistema Financeiro e Bancário. $2^{\circ}$ Edição, Rio de Janeiro: Editora Elsevier,2010.

OLIVEIRA, Ariovaldo Umbelino. A Geografia Agrária e as transformações territoriais recentes no campo brasileiro. In: CARLOS, A. F. Novos caminhos da Geografia. São Paulo: Contexto, 1999. p. 63-110.

RIBEIRO, Magno Alves. Manual Para Elaboração e Apresentação de Monografias. 1 ed. Tangará da Serra/MT: Sanches 2005.

SICREDI. Histórico. Disponível em: <http://www.sicredi.com.br/historico/index.html>. Acesso em 17.03.2012.

TURIBIO, Tulio Cesar da Fonseca. Análise da Concessão de Crédito Rural Via FCO Rural aos Produtores no Estado de Mato Grosso. Dissertação [Mestrado em agronegócios e desenvolvimento regional], Cuiabá: UFMT, 2010.

VERGARA, Sylvia Constant. Projetos e relatórios de pesquisa em administração. 5. ed. São Paulo: Atlas, 2011. 